University of Wollongong

Research Online

Faculty of Science - Papers (Archive)

Faculty of Science, Medicine and Health

$1-1-2009$

\title{
A fluorescence quenching assay to discriminate between specific and non- specific inhibitors of Dengue virus protease
}

C Bodenreider

D Beer

T Keller

S Sonntag

D Wen

See next page for additional authors

Follow this and additional works at: https://ro.uow.edu.au/scipapers

Part of the Life Sciences Commons, Physical Sciences and Mathematics Commons, and the Social and Behavioral Sciences Commons

\section{Recommended Citation}

Bodenreider, C; Beer, D; Keller, T; Sonntag, S; Wen, D; Yap, Li; Yau, Y H; Shocat, S G; Huang, D; Zhou, T; Caflisch, A; Su, X C; Ozawa, Kiyoshi; Otting, G; Vasudevan, S G.; Lescar, J; and Lim, S P.: A fluorescence quenching assay to discriminate between specific and non-specific inhibitors of Dengue virus protease 2009, 195-204.

https://ro.uow.edu.au/scipapers/869

Research Online is the open access institutional repository for the University of Wollongong. For further information contact the UOW Library: research-pubs@uow.edu.au 


\title{
A fluorescence quenching assay to discriminate between specific and non- specific inhibitors of Dengue virus protease
}

\begin{abstract}
In drug discovery, the occurrence of false positives is a major hurdle in the search for lead compounds that can be developed into drugs. A small-molecular-weight compound that inhibits dengue virus protease at low micromolar levels was identified in a screening campaign. Binding to the enzyme was confirmed by isothermal titration calorimetry (ITC) and nuclear magnetic resonance (NMR). However, a structureactivity relationship study that ensued did not yield more potent leads. To further characterize the parental compound and its analogues, we developed a high-speed, low-cost, quantitative fluorescence quenching assay. We observed that specific analogues quenched dengue protease fluorescence and showed variation in IC(50) values. In contrast, nonspecifically binding compounds did not quench its fluorescence and showed similar IC(50) values with steep dose-response curves. We validated the assay using single Trp-to-Ala protease mutants and the competitive protease inhibitor aprotinin. Specific compounds detected in the binding assay were further analyzed by competitive ITC, NMR, and surface plasmon resonance, and the assay's utility in comparison with these biophysical methods is discussed. The sensitivity of this assay makes it highly useful for hit finding and validation in drug discovery. Furthermore, the technique can be readily adapted for studying other protein-ligand interactions.
\end{abstract}

\section{Keywords}

quenching, assay, discriminate, between, specific, non, fluorescence, inhibitors, protease, dengue, virus

\section{Disciplines}

Life Sciences | Physical Sciences and Mathematics | Social and Behavioral Sciences

\section{Publication Details}

Bodenreider, C., Beer, D., Keller, T., Sonntag, S., Wen, D., Yap, L., Yau, Y., Shocat, S., Huang, D., Zhou, T., Caflisch, A., Su, X., Ozawa, K., Otting, G., Vasudevan, S. G., Lescar, J. \& Lim, S. P. (2009). A fluorescence quenching assay to discriminate between specific and non-specific inhibitors of Dengue virus protease. Analytical Biochemistry, 395 (2), 195-204.

\section{Authors}

C Bodenreider, D Beer, T Keller, S Sonntag, D Wen, Li Yap, Y H Yau, S G Shocat, D Huang, T Zhou, A Caflisch, X C Su, Kiyoshi Ozawa, G Otting, S G. Vasudevan, J Lescar, and S P. Lim 


\title{
A fluorescence quenching assay to discriminate between specific and nonspecific inhibitors of dengue virus protease
}

\author{
Christophe Bodenreider ${ }^{a}$, David Beer ${ }^{a}$, Thomas H. Keller ${ }^{a}$, Sebastian Sonntag ${ }^{a}$, Daying Wen ${ }^{a}$, LiJian Yap ${ }^{b}$, \\ Yin Hoe Yau ${ }^{\mathrm{b}}$, Susana Geifman Shochat ${ }^{\mathrm{b}}$, Danzhi Huang ${ }^{\mathrm{c}}$, Ting Zhou ${ }^{\mathrm{c}}$, Amedeo Caflisch ${ }^{\mathrm{c}}$, Xun-Cheng Su ${ }^{\mathrm{d}}$, \\ Kiyoshi Ozawa ${ }^{\mathrm{d}}$, Gottfried Otting ${ }^{\mathrm{d}}$, Subhash G. Vasudevan ${ }^{\mathrm{a}, 1}$, Julien Lescar ${ }^{\mathrm{b}}$, Siew Pheng Lim ${ }^{\mathrm{a}, *}$ \\ ${ }^{a}$ Novartis Institute for Tropical Diseases, Chromos 138670, Singapore \\ ${ }^{\mathrm{b}}$ School of Biological Sciences, Nanyang Technological University, Singapore 637551, Singapore \\ ${ }^{\mathrm{c}}$ Department of Biochemistry, University of Zürich, $\mathrm{CH}-8057$ Zürich, Switzerland \\ ${ }^{\mathrm{d}}$ Research School of Chemistry, Australian National University, Canberra ACT 0200, Australia
}

\section{A R T I C L E I N F O}

\section{Article history:}

Received 20 May 2009

Available online 13 August 2009

\section{Keywords:}

Fluorescence

Quenching

Assay

Identification

Promiscuous inhibitors

Dengue virus protease

\begin{abstract}
A B S T R A C T
In drug discovery, the occurrence of false positives is a major hurdle in the search for lead compounds that can be developed into drugs. A small-molecular-weight compound that inhibits dengue virus protease at low micromolar levels was identified in a screening campaign. Binding to the enzyme was confirmed by isothermal titration calorimetry (ITC) and nuclear magnetic resonance (NMR). However, a structure-activity relationship study that ensued did not yield more potent leads. To further characterize the parental compound and its analogues, we developed a high-speed, low-cost, quantitative fluorescence quenching assay. We observed that specific analogues quenched dengue protease fluorescence and showed variation in $\mathrm{IC}_{50}$ values. In contrast, nonspecifically binding compounds did not quench its fluorescence and showed similar $\mathrm{IC}_{50}$ values with steep dose-response curves. We validated the assay using single Trp-to-Ala protease mutants and the competitive protease inhibitor aprotinin. Specific compounds detected in the binding assay were further analyzed by competitive ITC, NMR, and surface plasmon resonance, and the assay's utility in comparison with these biophysical methods is discussed. The sensitivity of this assay makes it highly useful for hit finding and validation in drug discovery. Furthermore, the technique can be readily adapted for studying other proteinligand interactions.
\end{abstract}

(C) 2009 Elsevier Inc. All rights reserved.
High-throughput screening (HTS $)^{2}$ is a major method in drug discovery for new small lead molecules. In high-throughput enzyme

\footnotetext{
* Corresponding author. Fax: +65 67222916.

E-mail address: siew_pheng.lim@novartis.com (S.P. Lim).

1 Present address: Program in Emerging Infectious Diseases, Duke-NUS Graduate Medical School, Singapore 169547, Singapore.

${ }^{2}$ Abbreviations used: HTS, high-throughput screening; SAR, structure-activity relationship; DENV1-4, dengue virus serotypes 1 to 4 ; NS2/NS3, nonstructural protein 2/3; WNV, West Nile virus; YFV, yellow fever virus; FRET, Förster resonance energy transfer; Bz, benzoyl; PCR, polymerase chain reaction; HPLC, high-performance liquid chromatography; CF40-gly-NS3pro185, NS2B (amino acids 1394-1440) fused to NS3 protease domain (amino acids 1476-1660) via 9 amino acids (Gly ${ }_{4}$-Ser$\mathrm{Gly}_{4}$ ); LB, Luria-Bertani; IPTG, isopropyl $\beta$-d-thiogalactoside; PBT, phosphate-buffered saline containing $1 \%$ Triton X-100; SDS-PAGE, sodium dodecyl sulfatepolyacrylamide gel electrophoresis; Nle, norleucine; RFU, relative fluorescence units; AMC, 7-amino-4-methyl coumarin; SE, standard errors; ITC, isothermal titration calorimetry; BPTI, bovine pancreatic trypsin inhibitor; DMSO, dimethyl sulfoxide; RU, resonance units; NHS, $\mathrm{N}$-hydroxysuccinimide; EDC, 1-ethyl-3-diaminopropyl-carbodiimide; PDEA, 2-(2-pyridyldithio)ethaneamine; NMR, nuclear magnetic resonance; HSQC, heteronuclear single quantum correlation; NOE, nuclear Overhauser effect; WT, wild type; SPR, surface plasmon resonance; IFE, inner filter effect.
}

inhibition assays, more than a million compounds are usually tested for their ability to inactivate the target enzyme. Often the process involves two consecutive screens [1,2]. The first screen identifies compounds that inhibit the enzymatic activity and is usually performed at a single compound concentration. The second screen confirms the positive hits from the former one by measuring $\mathrm{IC}_{50}$ values (i.e., the concentration of compound needed to obtain 50\% inhibition of the enzyme in the in vitro assay). After the second round of screening, one may still be left with hundreds of lead candidates, many of which could be false positives [3].

Often one or more candidate lead compound classes are chosen as starting points for structure-activity relationship (SAR) studies. Compounds are chemically derivatized so as to improve their inhibitory capacity or $\mathrm{IC}_{50}$. $\mathrm{IC}_{50}$ measurements alone, however, contain no information on the inhibitory mechanism. It has been widely documented that an $\mathrm{IC}_{50}$ value can arise from many mechanisms besides specific inhibition such as target sequestration, compound aggregation, and interference with the enzymatic assay [4-6]. Thus, $\mathrm{IC}_{50}$ values may serve as a disqualifying parameter (if 
the compound is only weakly active) but cannot constitute the only qualifying parameter for identification of a lead compound given the occurrence of the false positives mentioned above.

It is crucial, therefore, to have additional screening methods in drug discovery to determine the specificity of a compound for the target so as to deliver high-quality candidate compounds for lead generation. Because dozens of compounds are usually evaluated during hit confirmation and hit-to-lead chemistry, additional screening methods must satisfy three requirements: (i) low cost (in terms of amounts of compound and protein needed), (ii) high throughput, and (iii) the ability to identify specific binding.

This article reports the development of a selective highthroughput binding assay in the context of anti-dengue drug discovery. Dengue virus (DENV) protease is an obvious target for anti-dengue drug development $[7,8]$ because it plays a key role in the replication of the virus by cleaving the viral polyprotein precursor after translation. The protease domain is contained in nonstructural protein 3 (NS3) [9], and its activity is greatly enhanced by interactions with the NS2B protein, which acts as its cofactor $[10,11]$. Several efforts to find inhibitors for different flavivirus proteases (West Nile virus [WNV], dengue, and yellow fever virus [YFV]) have been reported, with several studies focusing on peptidic substrate-based inhibitors [12-17]. Nonpeptidic inhibitors have been identified by in vitro screening [18-20] or in silico throughput docking [21]. Most of these compounds do not possess the appropriate properties for drug development, either because the scaffold is too labile $[15-17,19]$ or because the inhibitors bind too weakly $[18,20]$.

Our attempts to identify a nonpeptidic inhibitor of dengue protease led to establishment of a simple and efficient binding assay based on tryptophan fluorescence as described in this article. Compound binding in the protease catalytic pocket was detected by Förster resonance energy transfer (FRET) between the ligands and nearby Trp residues and was validated using single Trp-toAla protease mutants and the competitive inhibitor aprotinin. The assay provides quantitative compound binding affinities and identifies promiscuous inhibitors in an inexpensive way that is compatible with a high-throughput setup.

\section{Materials and methods}

\section{Materials}

All compounds (1-9, Bz-nKRR-H) were chemically synthesized in-house. Fluorogenic peptide substrate Bz-Nle-Lys-Arg-Arg-AMC was purchased from LSU Health Sciences Center (New Orleans, LA, USA), and bovine pancreatic trypsin inhibitor was purchased from Sigma-Aldrich (St. Louis, MO, USA). Polymerase chain reaction (PCR) was carried out using Turbo Pfu polymerase from Stratagene (La Jolla, CA, USA). Restriction enzymes and modifying enzymes were purchased from New England Biolabs (Beverly, MA, USA). Oligonucleotides were synthesized by Research Biolabs (Singapore).

\section{Chemistry}

All compounds generated in Fig. 1 were determined to have more than $95 \%$ purity by high-performance liquid chromatography (HPLC) (see Supplementary material).

\section{Cloning of DENV2 CF40-gly-NS3pro185 W mutant constructs}

All Trp mutants were generated with overlapping PCR using the plasmid DENV2 TSV01 pET15b-CF40-gly-NS3pro185 as a template [22]. To obtain cNS2B with Trp mutations, PCR was carried out using the forward primer NS2BcfXhol-F [22] and reverse primers W5A-REV, W50A-REV, W69A-REV, W83A-REV, and W89A-REV, respectively (see Table $S 1$ in Supplementary material). To obtain NS3pro185 with W mutations, PCR was carried out using the forward primers W5A-FOR, W50A-FOR, W69A-FOR, W83A-FOR, and W89A-FOR, respectively (see Table S1) and reverse primer NS3pro185BamHI-R [22]. The two products were joined in the second round of PCR using the primer pair NS2BcfXhol-F and NS3pro185BamHI-R to generate the individual CF40-glyNS3pro185 W mutants. The overlapped PCR products were digested with XhoI and BamHI and were ligated into the same sites in $\mathrm{pET} 15 \mathrm{~b}$.

\section{Protein expression and purification}

Expression and purification of DENV2 CF40-gly-NS3pro185 has been described previously [22]. Briefly, Escherichia coli BL21CodonPlus(DE3)-RIL (Stratagene) transformed with these plasmids were grown in Luria-Bertani (LB) broth supplemented with ampicillin $(100 \mathrm{mg} / \mathrm{ml})$ and chloramphenicol $(50 \mathrm{mg} / \mathrm{ml})$ at $37{ }^{\circ} \mathrm{C}$ until $\mathrm{OD}_{600}$ reached approximately 0.5 . Protein expression was induced with $0.4 \mathrm{mM}$ isopropyl $\beta$-D-thiogalactoside (IPTG) at $16{ }^{\circ} \mathrm{C}$ for $20 \mathrm{~h}$. Cells were harvested by centrifugation and resuspended in $4 \mathrm{ml}$ of phosphate-buffered saline containing 1\% Triton X-100 (PBT). Cells were lysed by sonication and debris was removed by centrifugation at $35,000 \mathrm{rpm}$ for $30 \mathrm{~min}$. The resulting protein solution was filtered through a $0.22-\mu \mathrm{m}$ filter and loaded onto a 5-ml HiTrap chelating HP column (Amersham Biosciences, Piscataway, NJ, USA) equilibrated with lysis buffer. The resin was washed with 10 column volumes of lysis buffer before bound proteins were eluted from the column with lysis buffer and a linear gradient of imidazole from 20 to $300 \mathrm{mM}$ in the same buffer. Peak fractions were analyzed by $10 \%$ sodium dodecyl sulfate-polyacrylamide gel electrophoresis (SDS-PAGE). Positive fractions were pooled, desalted, and concentrated with spin concentrators (Amicon Ultra15, molecular weight cutoff 10,000 Da, Millipore, Billerica, MA, USA).

\section{Enzymatic assay}

The assay has been described previously [14]. Briefly, activities of cNS2B/NS3pro complexes were measured in a Safire ${ }^{2}$ plate reader $($ Tecan $)\left(\lambda_{\mathrm{ex}}=385 \mathrm{nM}, \lambda_{\mathrm{em}}=465 \mathrm{nM}\right)$ and performed in a final volume of $50 \mu \mathrm{l}$ containing $50 \mathrm{mM}$ Tris- $\mathrm{HCl}$ (pH 7.5), $1 \mathrm{mM}$ Chaps, $20 \%$ glycerol, and $50 \mu \mathrm{M} \mathrm{Bz}$-Nle-Lys-Arg-Arg-AMC at $37^{\circ} \mathrm{C}$. Control reactions contained $50 \mathrm{nM}$ CF40-gly-NS3pro185. The proteolytic reaction was monitored by an increase in fluorescence (relative fluorescence units $[\mathrm{RFU}] / \mathrm{min}$ ) that was subsequently converted to $\mathrm{M} \cdot \mathrm{s}^{-1}$ from a standard 7-amino-4-methyl coumarin (AMC) calibration curve. Progression curves were fitted to Michaelis-Menten kinetics by nonlinear regression using GraphPad Prism (GraphPad Software, San Diego, CA, USA). Steady-state kinetic constants of each substrate were determined from triplicate measurements and are reported as means \pm standard errors (SE).

Inhibitors were assayed in a 96-well plate format using $50 \mathrm{mM}$ Tris- $\mathrm{HCl}(\mathrm{pH} 7.5)$ and $1 \mathrm{mM}$ Chaps in a final volume of $50 \mu \mathrm{l}$. Typically, protease (40 nM) was preincubated with concentrations ( 0 $100 \mu \mathrm{M}$ ) of test compounds at $37^{\circ} \mathrm{C}$ for $30 \mathrm{~min}$. The reaction was initiated by the addition of $20 \mu \mathrm{M}$ substrate Bz-nKRR-AMC. Reaction progress was monitored continuously by following the increase in fluorescence on a Tecan Safire ${ }^{2}$ plate reader. $\mathrm{IC}_{50}$ values of inhibitors were derived by fitting the calculated initial velocities to a nonlinear regression curve using GraphPad Prism software. Each point of the $\mathrm{IC}_{50}$ curve was measured in duplicate during a single experiment. 
<smiles>[R]c1ccc2c([R])nnc([R])c2c1</smiles><smiles>[R]C1CNC(c2ccc(N)cc2)=N1</smiles><smiles>Nc1ccc2c(c1)CNCC2</smiles>

$$
\mathrm{HN}
$$

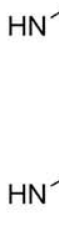<smiles>NCc1ccc(N)cc1</smiles><smiles>COC(=O)c1ccc(-c2ccc(N)cc2)cc1</smiles><smiles>Nc1ccc(C2=NCCN2)cc1</smiles>
$\mathrm{HN}$<smiles>[R]C1CNC(c2ccc(N)cc2)=N1</smiles><smiles>CN=C(N=CN)c1ccc(N)cc1</smiles><smiles>NC(C=[IH])C=NC1=NCCN1</smiles>

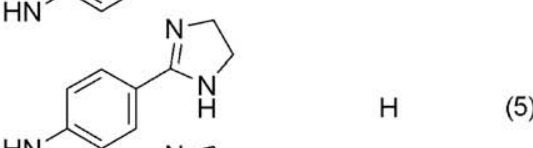<smiles></smiles><smiles>Nc1ccc(C2=NCCN2)cc1</smiles><smiles>Nc1ccc(C2=NCCN2)cc1</smiles>

R $\quad$ No.

$\mathrm{H}$

H (3)

$\mathrm{H}$

$\mathrm{H}$

No.

$\mathrm{NH}_{2}$

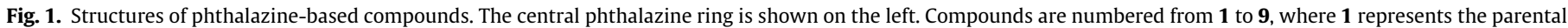
compound and $\mathbf{2}$ to $\mathbf{9}$ are representative modified derivatives described in the article.

\section{Buffer}

The buffer used for absorbance spectra, titration, and isothermal titration calorimetry (ITC) was $50 \mathrm{mM}$ Tris- $\mathrm{HCl}(\mathrm{pH} 7.5)$ and $50 \mathrm{mM} \mathrm{NaCl}$.

\section{Absorbance spectra}

Absorbance spectra of compounds were measured on a Tecan Safire $^{2}$. All compounds were diluted in $90 \mu \mathrm{l}$ of buffer to a final concentration of $100 \mu \mathrm{M}$ on a UV-Star 96-well microplate (Greiner Bio-One).

\section{Fluorescence-monitored titrations}

Two protein solutions were prepared (2-5 $\mu \mathrm{M}$ protein with and without $40 \mu \mathrm{M}$ compound) and were mixed in a microplate to obtain 12 different compound concentrations ranging from 0 to $40 \mu \mathrm{M}$ in approximately 3.5- $\mu \mathrm{M}$ steps. Then each dilution comprising $90 \mu \mathrm{l}$ was transferred to a UV-Star 96-well microplate. After $1 \mathrm{~h}$ incubation at room temperature, fluorescence was measured at $25^{\circ} \mathrm{C}$ on a Tecan Safire ${ }^{2}$ with $\lambda_{\mathrm{ex}}=280 \mathrm{~nm}$ and $\lambda_{\mathrm{em}}=340 \mathrm{~nm}$. The setting for slit widths depended on the protein concentration used. For $3 \mu \mathrm{M}$ protein, the slits were 10 and $20 \mathrm{~mm}$ for excitation and emission, respectively. At the end of the measurements, $11 \mu \mathrm{M}$ bovine pancreatic trypsin inhibitor (BPTI) was added to the wells containing $40 \mu \mathrm{M}$ compound and the fluorescence was remeasured. Binding curves were analyzed according the following two-state model describing the formation of a 1:1 complex:

$P+L \stackrel{K_{\mathrm{D}}}{\leftrightarrow} P L$

where $P$ is the protein concentration, $L$ is the ligand concentration, and $K_{\mathrm{D}}$ is the equilibrium dissociation constant.

The corresponding binding equation is

$I F=I F_{0}+\Delta I F \frac{\left(K_{\mathrm{D}}+P t+L t\right)-\sqrt{\left(K_{\mathrm{D}}+P t+L t\right)^{2}-4 L t \cdot P t}}{2 . P t}$

where $I F$ is the fluorescence intensity, $I F_{0}$ is the fluorescence intensity in the absence of ligand, $\Delta I F$ is the change in fluorescence intensity on ligand binding, $K_{\mathrm{D}}$ is the equilibrium dissociation constant, and $P t$ and $L t$ are the total protein and ligand concentrations, respectively. This equation was used to analyze the binding isotherms. The data were fitted using the nonlinear least squares option of GraphPad Prism software. 
Isothermal titration calorimetry

Calorimetry experiments were performed with an Auto-ITC microcalorimeter (Microcal). All titrations were done at $25^{\circ} \mathrm{C}$. For standard experiments, $6 \mu \mathrm{M}$ NS2B/NS3 protease was titrated with $10-\mu \mathrm{l}$ injections of $80 \mu \mathrm{M}$ BPTI. Each titration included an initial 1$\mu \mathrm{l}$ injection. The stirring speed used was $300 \mathrm{rpm}$, and the reference power was $10 \mu \mathrm{cal} / \mathrm{s}$. The heat of the last injection of each titration series was subtracted from the titration data to account for the heat of dilution. For competition experiments, compounds were added to the protein in the cell. Dimethyl sulfoxide (DMSO) was added to the BPTI solutions in the syringe to obtain equal DMSO concentrations in the cell and in the syringe. $K_{\mathrm{D}}$ values of the compounds from competition experiments with BPTI were estimated using the relationship [23]

$K_{\text {D-apparent }}=\frac{K_{\mathrm{D}-\mathrm{BPTI}}}{K_{\mathrm{D}-\mathrm{C}}}[\mathrm{C}]+K_{\mathrm{D}-\mathrm{BPTI}}$

where $\mathrm{C}$ is compound, $K_{\mathrm{D}-\mathrm{C}}$ is the true $K_{\mathrm{D}}$ value for the proteasecompound association, $K_{\mathrm{D}-\mathrm{BPTI}}$ is the $K_{\mathrm{D}}$ for the protease-BPTI association in the absence of compound, and $K_{\mathrm{D} \text {-apparent }}$ is the apparent $K_{\mathrm{D}}$ for the protease-BPTI association in the presence of compound.

\section{Surface plasmon resonance biosensor measurements}

Measurements were done on a Biacore 3000 instrument (Biacore, Uppsala, Sweden). DEN2 CF40-gly-NS3pro186 with a Cterminal Cys residue was immobilized via the engineered cysteine to a level of 7000 resonance units (RU) on a carboxymethyl-dextran sensor surface (CM5) using ligand-thiol coupling chemistry. For the following procedure, each step was performed sequentially at a flow rate of $10 \mu \mathrm{l} / \mathrm{min}$ : (i) 7-min injection of a mixture of $0.1 \mathrm{M}$ $\mathrm{N}$-hydroxysuccinimide (NHS) and 0.4 M 1-ethyl-3-diaminopropylcarbodiimide (EDC), (ii) 3-min injection of $80 \mathrm{mM} \mathrm{2-(2-pyridyldi-}$ thio)ethaneamine (PDEA), (iii) 3.5-min injection of $1.0 \mathrm{M}$ ethanolamine- $\mathrm{HCl}$, (iv) 5-min injection of CF40-gly-NS3pro186 in sodium acetate ( $\mathrm{pH} 4.0)$, and (v) 7-min injection of $50 \mathrm{mM}$ cysteine in $1 \mathrm{M} \mathrm{NaCl}$. The control surface was treated in an identical way, omitting the injection of the protein. The inhibitors were diluted with $50 \mathrm{mM}$ phosphate buffer ( $\mathrm{pH}$ 7.4) and 5\% DMSO (final concentration). The same buffer was used as running buffer throughout the experiment. Inhibitor concentrations ranging from 0.078 to $12.5 \mu \mathrm{M}$ were injected for $1 \mathrm{~min}$ sequentially over the reference and test flow cells at a flow rate of $30 \mu \mathrm{l} / \mathrm{min}$. Raw sensorgrams were reduced and solvent-corrected with a DMSO calibration curve $[24,25]$ using the Scubber software package (BioLogic Software, Campbell, Australia). Binding affinities were evaluated by fitting the data to the 1:1 Langmuir and steady-state models using BIAevaluation 4.1 (Biacore).

\section{Results}

\section{HTS/choice of lead compound/structure of inhibitor}

We previously reported the development of a highly sensitive and robust in vitro assay using the substrate Bz-nKRR-AMC for monitoring dengue single-chain NS2B/NS3 protease activity [22]. The assay was used to test peptidic inhibitors against DENV and WNV proteases $[13,15,16]$. We adapted it to a 1536 -well format and used it to screen our in-house library comprising approximately $10^{6}$ compounds. One class of compound was observed to inhibit DENV2 and WNV proteases with $\mathrm{IC}_{50}$ values of 2 and $3 \mu \mathrm{M}$, respectively. However, this compound class and its synthetic intermediates were highly insoluble, and the synthesis and testing of analogues proved to be challenging (data not shown).
A preliminary search for structurally related compounds yielded a second compound, $\mathbf{1}$, with a more readily amenable scaffold $\left(\mathrm{IC}_{50}\right.$ for DENV and $W N V=6$ and $24.5 \mu \mathrm{M}$, respectively) (Fig. 1). Binding of 1 to the catalytic pocket was verified by nuclear magnetic resonance (NMR) spectroscopy, where the presence of $\mathbf{1}$ led to a dramatically improved ${ }^{15} \mathrm{~N}-\mathrm{HSQC}$ (heteronuclear single quantum correlation) spectrum of DENV2 protease (see Fig. S1 in Supplementary material). In the absence of resonance assignments of the protease, this provides indirect evidence for binding of $\mathbf{1}$ to its catalytic pocket, and the same observation was made in ${ }^{15} \mathrm{~N}-\mathrm{HSQC}$ spectra of WNV protease. For WNV protease, NMR resonance assignments are available and intermolecular nuclear Overhauser effects (NOEs) indicate that $\mathbf{1}$ binds to its catalytic pocket [26].

We subsequently initiated chemistry efforts using compound $\mathbf{1}$ as the lead compound with the goal to generate a more potent DENV protease inhibitor. In addition, in the absence of a crystal structure of the DENV protease-inhibitor complex, the binding mode of compound $\mathbf{1}$ was obtained by automatic docking with a suite of programs SEED/FFLD and CHARMM minimization [27-30] using the structure of WNV protease bound with a tetrapeptide aldehyde inhibitor Bz-nKRR-H [31]. In this model, the central phthalazine ring is located in a cavity of the S1 pocket and forms a $\pi-\pi$ interaction with the phenyl group of Tyr161. Both charged imidazoline groups are involved in the formation of a salt bridge or hydrogen bonds with several residues (Asp129, Gly159, and Asn84). Furthermore, one of the NH groups linking the phenyl and phthalazine moieties forms a hydrogen bond with Pro131 backbone carbonyl oxygen. These results are in agreement with intermolecular NOEs reported for the homologous compound $\mathbf{5}$ [26].

The predicted binding mode of compound $\mathbf{1}$ in the protease catalytic site (Fig. 2A), as well as quantum mechanical calculations to determine the lowest energy state of compound $\mathbf{1}$ and derivatives thereof, was used to design more analogues.

Based on these data, approximately 130 compounds were subsequently synthesized. Several analogues inhibited DENV and WNV proteases at $\mathrm{IC}_{50}$ values in the low micromolar range (representative compounds are shown in Tables 1 and 2). Yet despite extensive efforts, none of the analogues synthesized possessed submicromolar inhibitory activities and no clear SAR emerged from these studies. It is not unusual for micromolar leads with unfavorable physical properties (e.g., solubility) to show flat SAR and turn out to be unsuitable for lead optimization. In this case, however, we had clear evidence that the lead compound was binding to the target protein; therefore, the absence of SAR was puzzling.

\section{$I C_{50}$ values for different DENV serotypes}

To expand our understanding of the inhibitory properties of this class of compounds, we tested a subset on proteases from the four different dengue serotypes (DENV1, $-2,-3$, and -4 ). NS2B/NS3 proteases from DENV1-4 share between $50 \%$ and $70 \%$ sequence identity [32], and NS3 amino acid residues forming the substrate binding pockets S1, S2, and S3 are mostly conserved [31]. Differences between the catalytic pockets of DENV1-4 arise from nonconserved NS2B amino acid residues that participate in the formation of S2 and S3 pockets [31]. These variations could conceivably alter the binding affinities of inhibitors by changing the NS2B structure or its ability to reorganize on ligand binding [31]. Indeed, $\mathrm{IC}_{50}$ values obtained with the peptidic inhibitor Bz-nKRR$\mathrm{H}$ varied from 1.4 to $11.8 \mu \mathrm{M}$ across DENV1-4 (Table 1 ). This is also in agreement with our previous finding that the overall catalytic efficacies of DENV1-4 proteases for the substrate Bz-Nle-Lys-ArgArg-AMC differed by two- to sevenfold [22]. 

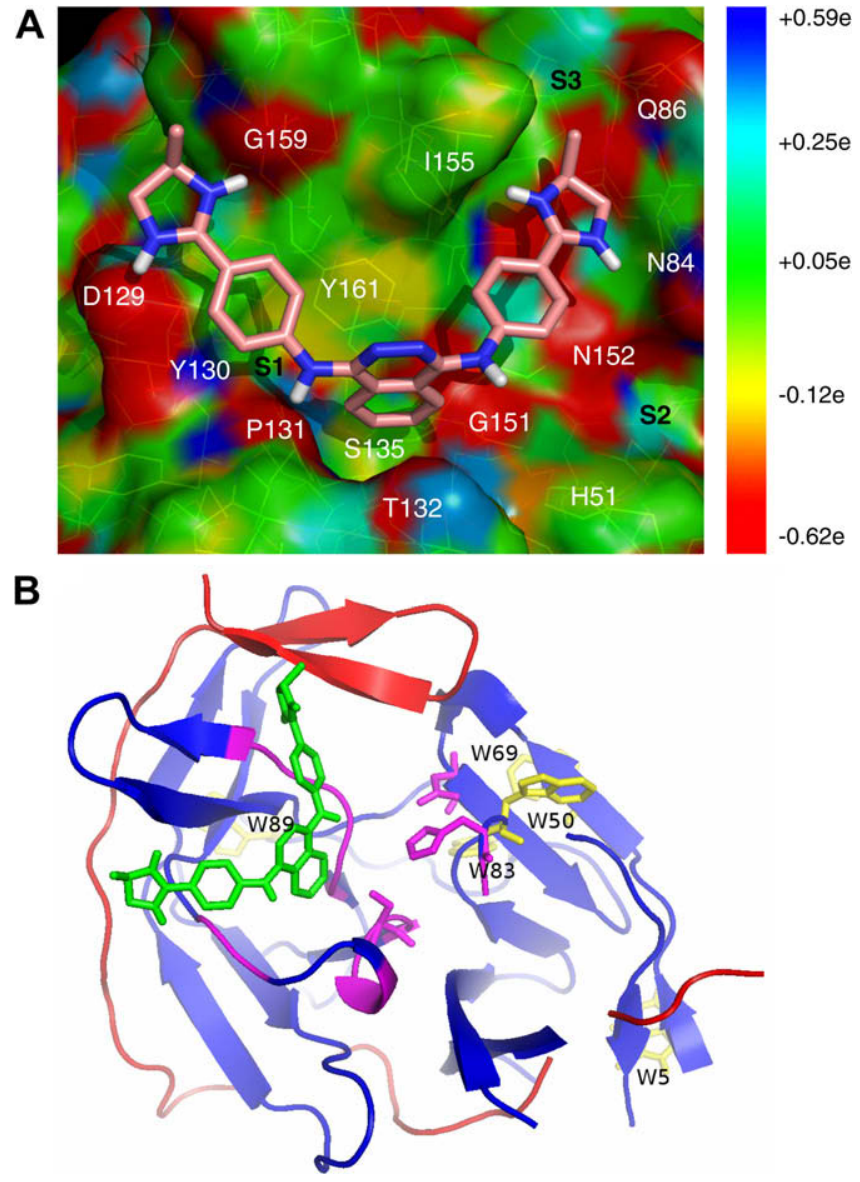

Fig. 2. Binding of compound 1 in WNV NS3/NS2B protease obtained by automatic docking with FFLD and CHARMM minimization [39]. (A) Close-up view of WNV NS3/NS2B in complex with compound 1. The protein surface (PDB code 2FP7) is colored according to atomic partial charges. Compound $\mathbf{1}$ is colored by atom type, and the hydrogens bound to carbon atoms are not shown. The central phthalazine ring is located in the $S 1$ pocket and forms a $\pi-\pi$ interaction with the phenyl group of Tyr161. Both charged imidazoline groups are involved in salt bridge or hydrogen bonds with several residues (Asp129, Gly159, and Asn84). One of the NH groups linking the phenyl and phthalazine moieties hydrogen bonds with Pro131 backbone carbonyl oxygen. e, elementary charge. (B) Location of trytophan residues in WNV NS2B/3 protease. The binding pose of compound $\mathbf{1}$ is shown by green sticks. NS2B is depicted as blue ribbons, and NS3 is depicted as red ribbons. Tryptophan residues are represented as yellow sticks and are labeled. The catalytic triad and the conserved residues of NS3 at the S1, S2, and S3 sites are magenta colored. The figures were made using PyMOL [40].

Among several structurally similar compounds, we found two different types of behaviors. One group, represented by inhibitors $\mathbf{1}, \mathbf{3}, \mathbf{5}$, and $\mathbf{8}$, showed selectivity among the different proteases with inhibition curves that exhibited Hill slopes ranging from 1 to 2 . The second group, represented by compounds $\mathbf{2}$ and $\mathbf{7}$, had similar inhibitory effects on different proteases and consistently displayed Hill slopes much larger than 1 (Table 1), suggesting that they act as nonspecific inhibitors. Compounds 4, 6, and 9 were poorly inhibitory or noninhibitory (Table 1 ).

\section{Trp fluorescence}

DENV2 NS2B/NS3pro contains five Trp residues (W5, W50, W69, W83, and W89) in the NS3pro moiety and one Trp residue in the NS2B cofactor (W23). Because no three-dimensional structure of DENV2 NS2B/NS3pro in complex with a ligand is available, Fig. 2B illustrates the locations of the Trp residues in the structure of the homologous WNV NS2B/NS3pro (PDB accession code 2FP7 [31]). All Trp residues of DENV2 NS2B/NS3pro are also present in WNV NS2B/NS3pro [31]. None of the Trps is in the protease catalytic pocket, and the model of the complex with compound 1 suggests the absence of any direct contacts between $\mathbf{1}$ and any of the Trp residues. Nonetheless, to test whether Trp fluorescence could be used to monitor compound binding, we used $\mathbf{1}$ as a reference compound. The absorbance spectrum of $\mathbf{1}$ has two main absorption bands at 300 and $380 \mathrm{~nm}$ (Fig. 3) and overlaps with Trp emission, usually at 305 to $360 \mathrm{~nm}$. When bound to the protease active site, compound 1 can potentially influence the fluorescence of the nearby Trp residues by a FRET. Because $\mathbf{1}$ has negligible intrinsic fluorescence (data not shown), its binding can be followed by monitoring the decrease in fluorescence signal intensity of the Trp residues.

\section{Binding of compound 1}

We titrated $4 \mu \mathrm{M}$ DENV2 NS2B/NS3pro with $1(0-40 \mu \mathrm{M})$ and monitored fluorescence emission at $340 \mathrm{~nm}$ (excitation at $280 \mathrm{~nm}$ ). The addition of $\mathbf{1}$ led to fluorescence quenching of the Trp residues in the protease (Fig. 4A). The effect was not caused by a change in the environment of the Trp side chains given that their emission wavelength maximum $\left(\lambda_{\max }\right)$ remained unchanged. A plot of fluorescence intensity versus inhibitor concentration showed a classical binding isotherm (Fig. 4B). Nevertheless, the observed shallow shape of the binding isotherm indicated that the protein concentration used was comparable to or below the $K_{\mathrm{D}}$ value of the inhibitor, thereby preventing a good estimate of binding stoichiometry. Therefore, 1:1 binding stoichiometry was assumed for all fits to allow comparison among different compounds. The $K_{\mathrm{D}}$ value obtained for $\mathbf{1}$ was $6 \pm 2.6 \mu \mathrm{M}$ and is comparable to its $\mathrm{IC}_{50}$ value obtained in the enzyme assay (Table 2 ).

Table 1

Results from in vitro testing of compounds on DENV1-4 proteases using substrate Bz-Nle-Lys-Arg-Arg-AMC.

\begin{tabular}{|c|c|c|c|c|c|c|c|c|}
\hline \multirow[t]{2}{*}{ Compound } & \multicolumn{2}{|l|}{ DENV1 } & \multicolumn{2}{|l|}{ DENV2 } & \multicolumn{2}{|l|}{ DENV3 } & \multicolumn{2}{|l|}{ DENV4 } \\
\hline & $\mathrm{IC}_{50}(\mu \mathrm{M})$ & Hill slope & $\mathrm{IC}_{50}(\mu \mathrm{M})$ & Hill slope & $\mathrm{IC}_{50}(\mu \mathrm{M})$ & Hill slope & $\mathrm{IC}_{50}(\mu \mathrm{M})$ & Hill slope \\
\hline 1 & 36.4 & 1.0 & $6.0 \pm 2.6$ & 0.8 & 17.5 & 0.9 & 32.8 & 0.9 \\
\hline 2 & 2.0 & 2.4 & $2.3 \pm 0.6$ & 5.1 & 1.6 & 3.9 & 2.0 & 5.6 \\
\hline 3 & 10.7 & 1.8 & $1.1 \pm 0.2$ & 0.4 & 8.5 & 1.1 & 13.6 & 1.6 \\
\hline 4 & 233 & 1.4 & 27.4 & 0.9 & 100 & 0.9 & 64.8 & 1.3 \\
\hline 5 & 12.3 & 2.4 & $5.8 \pm 2.3$ & 1.6 & 8.7 & 1.4 & 8.2 & 2.3 \\
\hline 6 & 170 & 0.9 & 55 & 0.5 & 86 & 0.7 & 43 & 1.3 \\
\hline 7 & 2.72 & 2.64 & $1.6 \pm 0.8$ & 3.2 & 1 & 3.3 & 1.3 & 5.2 \\
\hline 8 & 21.4 & 1.8 & $10.2 \pm 6.0$ & 0.9 & 27.9 & 1.2 & 19.8 & 2.4 \\
\hline 9 & $>100$ & NA & $>100$ & NA & $>100$ & NA & $>100$ & NA \\
\hline Bz-nKRR-H & $11.8 \pm 0.9$ & 1.05 & $8.9 \pm 0.5$ & 1.06 & $7.9 \pm 3$ & 1.15 & $1.4 \pm 0.5$ & 0.80 \\
\hline
\end{tabular}

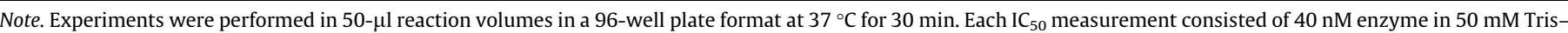

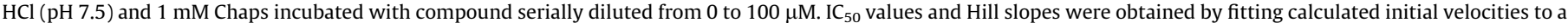
nonlinear regression curve using GraphPad Prism software. Each data point was measured in duplicate wells. NA, not applicable. 
Table 2

Results from in vitro inhibition and binding experiments of compounds to DENV2 and WNV proteases.

\begin{tabular}{|c|c|c|c|c|c|c|c|c|}
\hline Compound & $\begin{array}{l}\text { DENV2 } \mathrm{IC}_{50} \\
(\mu \mathrm{M})\end{array}$ & $\begin{array}{l}\text { DENV2 } K_{\mathrm{D}} \\
(\mu \mathrm{M})^{\mathrm{a}}\end{array}$ & $\begin{array}{l}\text { DENV2 competition } \\
\text { ITC }^{\text {b }}\end{array}$ & $\begin{array}{l}\text { DENV2 } K_{\mathrm{D}}(\mu \mathrm{M}) \\
\text { by ITC }\end{array}$ & $\begin{array}{l}\text { DENV2 } K_{\mathrm{D}}(\mu \mathrm{M}) \\
\text { by SPR }\end{array}$ & $\begin{array}{l}\text { WNV IC } 50 \\
(\mu \mathrm{M})\end{array}$ & Hill slope & $\begin{array}{l}\text { WNV } K_{\mathrm{D}} \\
(\mu \mathrm{M})\end{array}$ \\
\hline 1 & $6 \pm 2.6$ & $7.2 \pm 3.2(\mathrm{Y})$ & $\mathrm{Y}$ & 7.3 & 3.7 & 24.5 & 3.5 & 21 \\
\hline 2 & $2.3 \pm 0.6$ & $\mathrm{NB}(\mathrm{N})$ & $\mathrm{N}$ & NB & NB & $3.6 \pm 1.8$ & 2.6 & NB \\
\hline 3 & $1.1 \pm 0.2$ & $7.7 \pm 2.0(Y)$ & $\mathrm{Y}$ & 13 & 0.3 & 22 & 1.4 & 90 \\
\hline 4 & 27.4 & $22.9(\mathrm{Y})$ & nd & nd & nd & 5.2 & 1.0 & 4.6 \\
\hline 5 & $5.8 \pm 2.3$ & $18.6(\mathrm{Y})$ & $\mathrm{Y}$ & 17 & $>100$ & 10.6 & 1.9 & 100 \\
\hline 6 & 55 & $54(\mathrm{Y})$ & nd & nd & nd & 6.2 & 1.1 & 7 \\
\hline 7 & $1.6 \pm 0.8$ & NB $(\mathrm{N})$ & $\mathrm{N}$ & NB & nd & 2.2 & 3.0 & NB \\
\hline 8 & $10.2 \pm 6.0$ & $16.3 \pm 0.3(\mathrm{Y})$ & Y & 40 & 4.3 & 16 & 2.0 & nd \\
\hline 9 & $>100$ & $100(\mathrm{~N})$ & $\mathrm{N}$ & NB & NB & nd & nd & nd \\
\hline
\end{tabular}

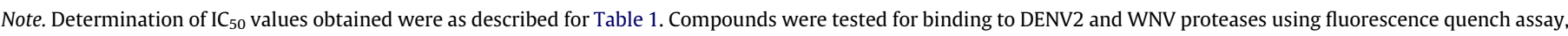
ITC, and SPR as described in Materials and methods.

a $\mathrm{Y}$ (yes) and $\mathrm{N}$ (no) indicate whether or not competition was observed between compound and BPTI.

b Competition ITC reflects a qualitative judgment of the competition data based on both change in $K_{\mathrm{D}}$ and change in binding enthalpy. $\mathrm{Y}$ and $\mathrm{N}$, see note a; NB, no binding; nd, experiment not done.

c For compound 1, the $K_{\mathrm{D}}$ value was calculated based on a single concentration of compound $\mathbf{1}$, whereas the $K_{\mathrm{D}}$ values for compounds $\mathbf{3}$ and $\mathbf{8}$ were determined from several compound concentrations using Eq. (2).

Further evidence for binding of $\mathbf{1}$ to the NS2B/NS3pro catalytic pocket was provided by using BPTI or aprotinin [33], which is a known competitive ligand of the protease. BPTI did not induce any fluorescence change on binding to the protease (data not shown). When BPTI was added to wells containing DENV2 NS2B/ NS3pro and compound 1, we observed an increase of fluorescence (Fig. 4B). This indicates that BPTI can displace the binding of $\mathbf{1}$ and confirms that the latter binds in the same pocket as BPTI. Competitive binding was also observed with the peptidic inhibitor BznKRR-H [31] (data not shown).

\section{Which Trp residue is targeted in the quenching experiments?}

To decipher which Trp residue was targeted by the quenching experiments, we systematically mutated the five Trp residues of DENV2 NS3pro (W5, W50, W69, W83, and W89) to alanine and titrated the mutant proteins with compound 1. Normalized titration curves revealed that the mutants and wild type (WT) showed similar $K_{\mathrm{D}}$ values for 1 ranging from 5 to $8 \mu \mathrm{M}$ (Fig. $4 \mathrm{C}$ ), with the exception of the W83A mutant (data not shown). The crystal structures of DENV and WNV proteases show that W83 is buried, suggesting that W83A mutation destabilizes the protein structure. W83A was also the least active mutant, with only $1 \%$ of the WT activity (data not shown). Thus, the role of W83 in the fluorescence studies could not be assessed accurately.

In contrast, the other mutants allowed us to pinpoint Trp residues affected by inhibitor binding. Most of the fluorescence change

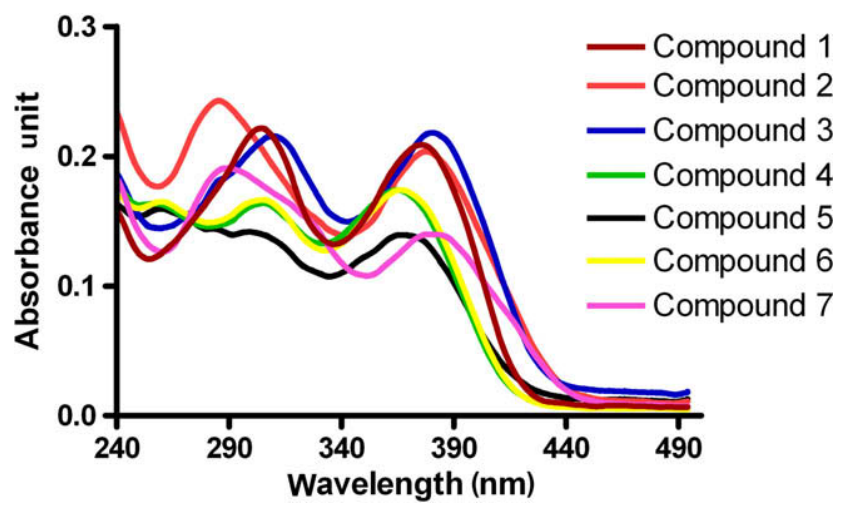

Fig. 3. Absorbance spectra of compounds $\mathbf{1}$ to $\mathbf{7}(100 \mu \mathrm{M})$ measured on a 96 -well plate with a microplate reader. Compound numbers are indicated. from binding of compound 1 could be attributed to W50 because mutating this residue to alanine resulted in the least change in fluorescence signals on titration with compound 1 (Fig. 4C). This is not surprising given that W50 is in direct proximity of the binding site [31] (residue H51 is part of the catalytic triad). Thus, the titration experiment with W50A further ascertained that 1 was binding to the catalytic pocket. W69 and W89 are also involved in compound-induced FRET given that mutating these to alanine likewise resulted in reduction in quenching of the protein intrinsic fluorescence on titration with compound 1. In contrast, fluorescence was unchanged in W5A on titration with compound $\mathbf{1}$, implying that this residue plays a negligible role in the signal change.

\section{Compounds binding to DENV2 protease}

For SAR analysis, fluorescence titrations were performed with 63 compounds. Some representative absorbance spectra of the compounds are shown in Fig. 3. Because the parent compound 1 had the optical properties required to quench tryptophan fluorescence, most of the structurally related analogues (all bearing the central phthalazine rings) from the SAR study had the same property. Six of these titrations are represented in Fig. 5A, and the $K_{\mathrm{D}}$ values obtained are listed in Table 2 . These compounds spanned a wide range of $\mathrm{IC}_{50}$ values $(1-55 \mu \mathrm{M})$. To our surprise, only one of the four compounds with good $\mathrm{IC}_{50}$ values showed good binding $\left(3, \mathrm{IC}_{50}=1.1 \mu \mathrm{M}, K_{\mathrm{D}}=7.7 \mu \mathrm{M}\right)$. The binding affinity of $\mathbf{3}$ was similar to that of $\mathbf{1}$ despite a fivefold difference in their $\mathrm{IC}_{50}$ values. Of the remaining three compounds, one showed intermediate binding ( $\mathbf{5}$, $\left.\mathrm{IC}_{50}=5.8 \mu \mathrm{M}, K_{\mathrm{D}}=18.6 \mu \mathrm{M}\right)$, whereas two showed no binding ( 2 and 7, $\mathrm{IC}_{50}=2.3$ and $1.6 \mu \mathrm{M}$, respectively). Titration of these compounds with BPTI resulted in displacement of only $\mathbf{3}$ and $\mathbf{5}$, confirming that only these compounds are competitive binders. No displacement of BPTI was observed with compounds 2 and 7. These results are in agreement with the steep Hill slopes observed in the inhibition curves of DENV1-4 proteases for the latter two compounds. On the other hand, $K_{\mathrm{D}}$ values for two compounds that showed intermediate binding (4 and $8, K_{\mathrm{D}}=22.9$ and $16.3 \mu \mathrm{M}$, respectively) correlated well with their $\mathrm{IC}_{50}$ values, and likewise, two poorly inhibitory compounds (6 and $\mathbf{9}, \quad \mathrm{IC}_{50}=55$ and $>100 \mu \mathrm{M}$, respectively) were also found to be weak binders or nonbinders. When BPTI was added to the wells after each titration, competition was observed for compounds $\mathbf{4 , 6}$, and 8 but not $\mathbf{9}$, demonstrating their different binding specificities. 

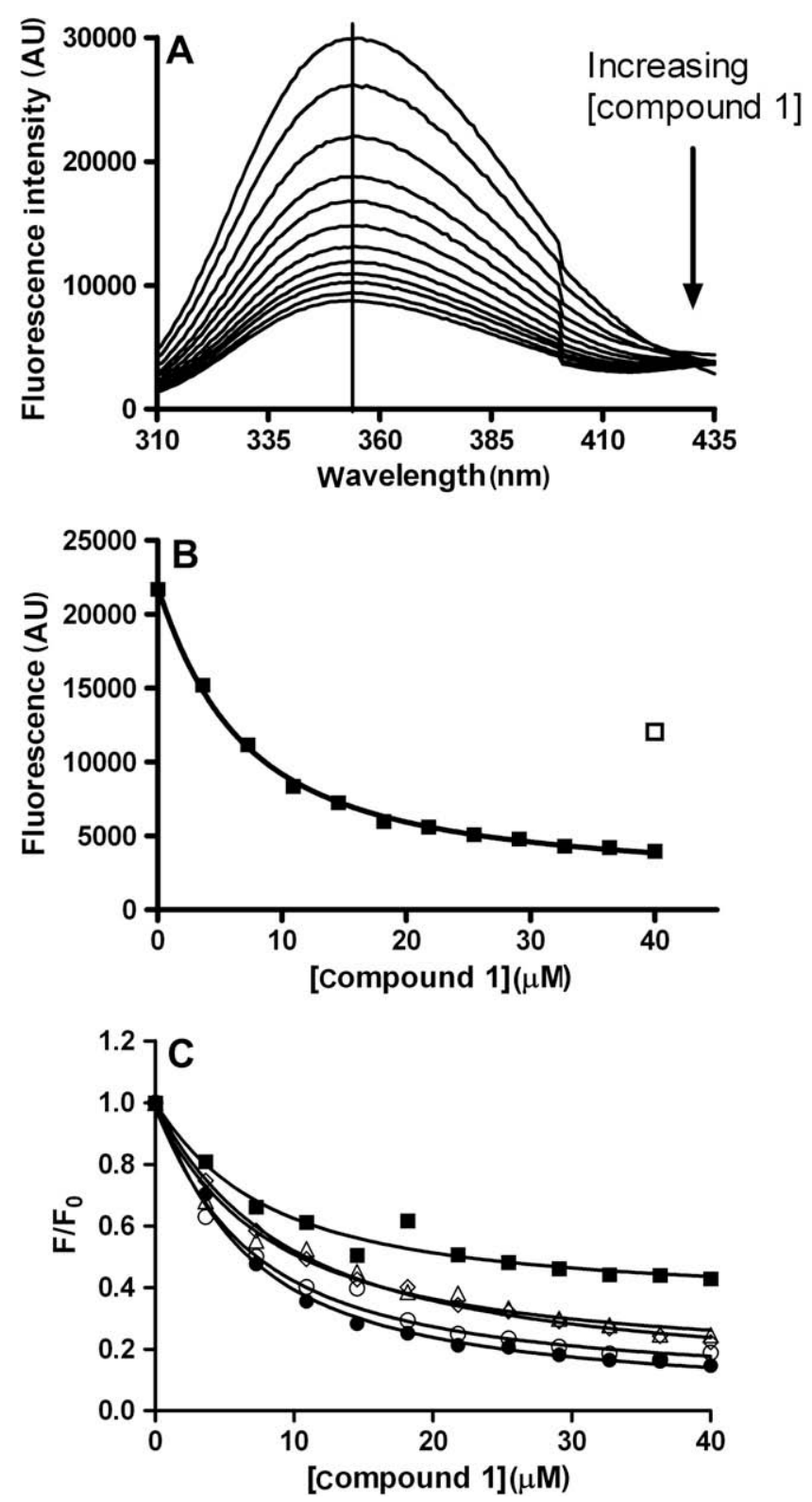

Fig. 4. Titration of DENV2 protease with compound 1. (A) Fluorescence spectra of DENV2 protease at various protein concentrations. The kinks in the spectra at 400 $\mathrm{nm}$ are an artifact of the microplate reader. AU, arbitrary units. (B) Titration of WT DENV2 protease with compound 1 monitored by fluorescence at $340 \mathrm{~nm}$. The solid line is the fit of the data to Eq. (1). The symbol ( $\square$ ) shows the level of fluorescence reached after the addition of $11 \mu \mathrm{M}$ BPTI to the well containing WT protein and 40 $\mu \mathrm{M}$ compound 1. (C) Titration of WT and W mutants with compound 1. Shown is normalized fluorescence at $340 \mathrm{~nm}$ (measured fluorescence $[F]$ divided by the fluorescence measured in the absence of compound $\left.\left[F_{0}\right]\right)$. The solid lines are the fit of the data to Eq. (1). Symbols: WT $(\bullet)$; W5A (O); W50A ( $\mathbf{\square})$; W69A $(\Delta)$; W89A $(\diamond)$. The resulting $K_{\mathrm{D}}$ values were $4.7,5.15,6.2,6.6$, and $7.8 \mu \mathrm{M}$, respectively.

\section{Compounds binding to WNV protease}

WNV and DENV proteases are homologous proteins but show different sensitivities toward different compounds. For example, compound 6 displayed a relatively low $\mathrm{IC}_{50}$ value for WNV protease $(6.2 \mu \mathrm{M})$ but not for DENV2 $(55 \mu \mathrm{M})$ (Table 2). This raised the question as to whether the tryptophan fluorescence assay would detect these differences. The same fluorescence quenching experiments can be applied for WNV and DENV proteases because tryptophans are present in both proteins at the same positions. We titrated WNV with the compounds as before and obtained a $K_{\mathrm{D}}$ va-
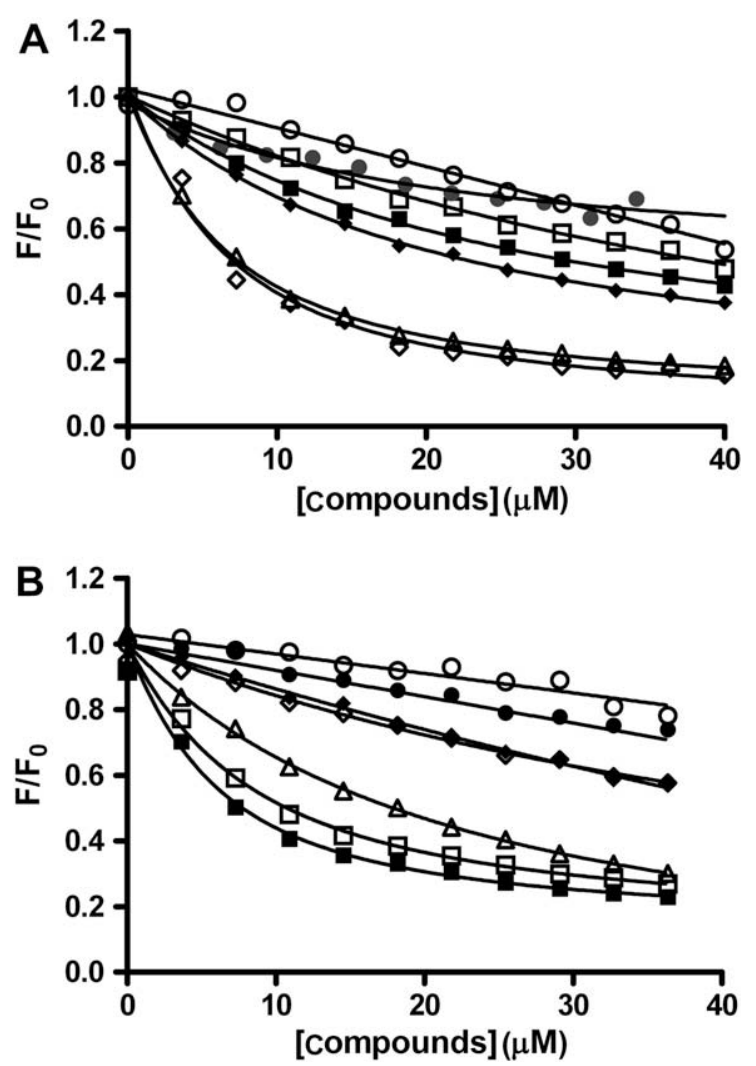

Fig. 5. Fluorescence titrations performed with several compounds. Titration data were normalized by dividing the measured fluorescence $(F)$ by the fluorescence measured in the absence of compound $\left(F_{0}\right)$. (A) Titration of DENV2 protease. (B) Titration of WNV protease. Solid lines show the fit of the data to Eq. (1). Titrations with different compounds are represented as follows: $\mathbf{1}(\Delta) ; \mathbf{2}(\bullet) ; \mathbf{3}(\diamond) ; \mathbf{4}(\mathbf{\square}) ; \mathbf{5}$ $(\diamond) ; \quad \square) ; 7(\bigcirc)$.

lue for compound $\mathbf{1}$ that was similar to its $\mathrm{IC}_{50}$ value (Fig. $5 \mathrm{~B}$ and Table 2). Interestingly, two compounds that were weak inhibitors and binders to DENV2 protease displayed good $\mathrm{IC}_{50}$ values and good binding affinities to WNV protease (compounds $\mathbf{4}$ and $\mathbf{6}$, $K_{\mathrm{D}}=4.6$ and $7.0 \mu \mathrm{M}$, respectively). Conversely, some of the compounds that were more potent against DENV than WNV bound only weakly to the WNV protease and showed poor $K_{\mathrm{D}}$ values for the latter (compounds 3 and $5, K_{\mathrm{D}}=90$ and $100 \mu \mathrm{M}$, respectively). Finally, compounds $\mathbf{2}$ and 7, which showed comparable $\mathrm{IC}_{50}$ values in DENV2 and WNV, also did not bind to WNV.

\section{Isothermal titration calorimetry}

ITC was used to corroborate the binding affinities obtained by tryptophan fluorescence. Due to low compound binding affinities and low solubilities, no satisfactory data were obtained in ITC experiments where the compounds were directly titrated to the DENV2 protease. To circumvent this experimental barrier, we performed competition ITC using BPTI. Titration of $6 \mu \mathrm{M}$ protease with $80 \mu \mathrm{M}$ BPTI resulted in exothermic binding and gave $K_{\mathrm{D}}=19 \mathrm{nM}, n=1.19$, and $\Delta H=-5.5 \mathrm{kcal} / \mathrm{mol}$ (Fig. 6). Competition experiments were performed by titrating the protein-BPTI complex with different compounds. Fig. 6 shows representative examples of titrations performed with compounds $\mathbf{3}, \mathbf{8}$, and $\mathbf{9}$. Compound 9 was used as a control because it did not inhibit the protease activity and did not show any binding to the protease by fluorescence (Table 2). The addition of $100 \mu \mathrm{M}$ compound 9 did not induce any significant change in the apparent $K_{\mathrm{D}}$ or on the binding enthalpy of BPTI ( $30 \mathrm{nM}$ or $-5.4 \mathrm{kcal} / \mathrm{mol}$, respec- 


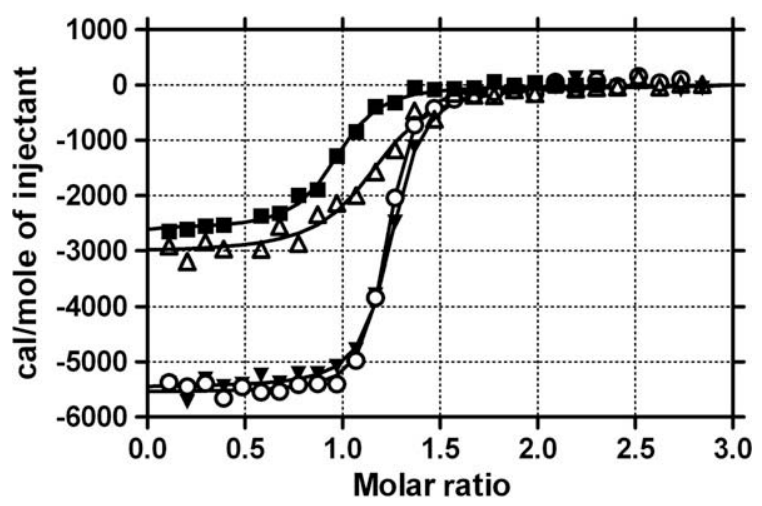

Fig. 6. ITC competition titration. Titrations of $6 \mu \mathrm{M}$ DENV2 protease with 28 consecutive $10-\mu \mathrm{l}$ injections of $80 \mu \mathrm{M}$ BPTI at $25^{\circ} \mathrm{C}$ were performed in the presence of various concentrations of compounds. Typical titrations are shown in the absence of compound $(\bigcirc)$ and in the presence of $150 \mu \mathrm{M}$ compound $8(\mathbf{\square}), 100 \mu \mathrm{M}$ compound $\mathbf{3}(\Delta)$, and $100 \mu \mathrm{M}$ compound $\mathbf{9}(\boldsymbol{\nabla})$.

tively). In contrast, $100 \mu \mathrm{M}$ compound 3 and $150 \mu \mathrm{M}$ compound 8 resulted in the following respective changes in BPTI binding: $K_{\mathrm{D}}=125 \mathrm{nM}$ and $\Delta H=-3 \mathrm{kcal} / \mathrm{mol} ; K_{\mathrm{D}}=77 \mathrm{nM}$ and $\Delta H=$ $-2.6 \mathrm{kcal} / \mathrm{mol}$. Other compounds were also tested for competition by ITC (Table 2). In summary, based on changes observed in the apparent $K_{\mathrm{D}}$ and/or on the binding enthalpy for BPTI, compounds that clearly competed with BPTI binding were $\mathbf{1}, \mathbf{3}, \mathbf{5}$, and $\mathbf{8}$, whereas noncompeting compounds were $\mathbf{2}$ and $\mathbf{9}$. Results from ITC experiments concurred with the previous fluorescence quenching data in that compounds $\mathbf{1}, \mathbf{3}, \mathbf{5}$, and $\mathbf{8}$ were identified as specific protease binders. Conversely, compounds that showed no binding in fluorescence were also negative in ITC ( 2 and $\mathbf{7}$ ).

\section{Surface plasmon resonance}

Binding affinities between compounds $\mathbf{1}, \mathbf{2}, \mathbf{3}, \mathbf{5}, \mathbf{8}$, and 9 and DENV2 protease were evaluated using a surface plasmon resonance (SPR) biosensor. DENV2 protease was immobilized on the matrix via an engineered C-terminal cysteine, and increasing concentrations of compounds were passed across ( $78 \mathrm{nM}$ to $12.5 \mu \mathrm{M}$ ). The results are summarized in Table 2 . In general, the compounds showed fast on and off rates in this concentration range. Compounds $\mathbf{1}$ and $\mathbf{8}$ gave satisfactory sensorgrams, allowing a straightforward analysis. Binding affinity for compound $\mathbf{1}$ was evaluated by fitting the data to the 1:1 Langmuir (see Fig. S2 in Supplementary material) and steady-state models (data not shown), returning similar $K_{\mathrm{D}}$ values of 3.75 and $2 \mu \mathrm{M}$, respectively. However, at concentrations above $12.5 \mu \mathrm{M}$, we observed deviations from the $1: 1$ fit, presumably due to nonspecific binding to the immobilized protein or carboxymethyl matrix. A competition assay showed that BPTI completely displaced 1 from its binding site on the protease (see Fig. S3). This corroborated results from other biophysical methods tested that compound $\mathbf{1}$ shares part of the binding site of BPTI.

Following a steady-state model, compound $\mathbf{8}$ yielded a $K_{\mathrm{D}}$ value of $4.3 \mu \mathrm{M}$. Compounds $\mathbf{2}, \mathbf{3}, \mathbf{5}$, and $\mathbf{9}$ displayed evidence of nonspecific interactions. Following the addition of $150 \mathrm{mM} \mathrm{NaCl}$ to the phosphate buffer, specific binding was observed for compound $\mathbf{3}$ $\left(K_{\mathrm{D}}=0.3 \mu \mathrm{M}\right)$ but not for compound $5\left(K_{\mathrm{D}}>100 \mu \mathrm{M}\right)$. Nonspecific binding persisted for compounds $\mathbf{2}$ and $\mathbf{9}$.

\section{Discussion}

Our study highlights the importance in drug discovery to confirm $\mathrm{IC}_{50}$ measurements with binding assays. The Trp fluorescence quenching assay presented here provided information on the binding mode of the compounds, including their binding site and the tightness of association. Using this assay, we systematically measured the binding affinities of 63 compounds generated from the SAR study and compared the $K_{\mathrm{D}}$ values obtained with their $\mathrm{IC}_{50}$ values (data not shown). We observed that, in a number of instances, small modifications of compound structures led to dramatic changes in specificity of inhibition. These changes were not always detectable by $\mathrm{IC}_{50}$ measurements. Nine key compounds were further characterized and are presented in this article.

We believe that changes in intrinsic fluorescence of the protease on compound binding was caused by a FRET mechanism where the compounds acted mainly as Trp fluorescence acceptors and were not due to an effect on Tyr residues. First, compound binding experiments that were performed with an excitation wavelength of $295 \mathrm{~nm}$ where Tyr was not excited gave similar binding isotherms and $K_{\mathrm{D}}$ values as experiments performed at $280 \mathrm{~nm}$. Second, studies with Trp-to-Ala mutants showed that fluorescence change induced on compound binding was due mostly to W50 in the NS3 moiety. W50 is the Trp residue nearest to the active site, and in the cocomplexed WNV protease Bz-nKRR-H crystal structure [31] the $\mathrm{C}-\alpha$ distance between W50 and the center of the peptide is approximately 10 to $15 \AA$. Förster distances $F_{\mathrm{R}}$ (where $F_{\mathrm{R}}$ corresponds to the distance where 50\% FRET efficacy is observed) of 6 to 12 and $21 \AA$ A have been reported for Trp-Trp homotransfer and Trp-dansyl pairs [34], respectively. Because the distance between W50 and the compound falls within this range, the significant FRET observed is fully expected.

A potential pitfall associated with fluorescence spectroscopy is the inner filter effect (IFE) that arises when the absorbance of the sample becomes too high at the excitation and emission wavelengths. The IFE causes a nonlinearity of the fluorescence signal that can be estimated by

$I F_{\mathrm{obs}}=I F \times 10^{-\frac{\left.A_{\mathrm{ex}}+A_{\mathrm{em}}\right)}{2},}$

where $I F_{\text {obs }}$ is the measured fluorescence, $I F$ is the fluorescence after IFE correction, and $A_{\mathrm{ex}}$ and $A_{\mathrm{em}}$ are the absorbances at the excitation and emission wavelengths, respectively [35]. The compounds tested in this study absorbed at both 280 and $340 \mathrm{~nm}$ so that, in principle, IFE could have contributed to the signal change observed. A control experiment where $15-\mu \mathrm{M}$ solutions of $\mathrm{N}$-acetyl-tryptophanamide were titrated with four of the compounds showed, however, that IFE is only minimally responsible for the fluorescence decrease (see Fig. S4 in Supplementary material). Therefore, the hyperbolic shapes observed in the titration experiments of the protease were indeed due to specific binding.

Our goal in developing a binding assay based on Trp fluorescence was to screen out nonspecific inhibitors and to ascertain whether compounds were binding competitively to the enzyme. A total of 63 compounds were tested in our study for their inhibitory capabilities $\left(\mathrm{IC}_{50}\right)$ and their binding affinities $\left(K_{\mathrm{D}}\right)$. This approach identified promiscuous inhibitors, and using BPTI we demonstrated that only a subset of compounds with low $K_{\mathrm{D}}$ were truly competitive binders (data not shown). Inclusion of Triton $\mathrm{X}$ 100 in the assay can often discriminate specific from nonspecific inhibitors that act via the formation of colloidal aggregates $[5,6]$. However, not all enzyme assays can tolerate the addition of Triton $\mathrm{X}-100$. Moreover, because the promiscuous nature of some inhibitors also depends on the protein target, this method cannot eliminate all false positives [3]. Our attempts to eliminate nonspecific binders by the addition of Triton X-100 in the enzyme assay was not very successful given that even the reference inhibitor BznKRR-H showed at least fivefold change in $\mathrm{IC}_{50}$ values in the presence of the detergent (data not shown). 
Compound 1, which was the parental compound from which SAR was developed, showed comparable $\mathrm{IC}_{50}(6 \pm 2.6 \mu \mathrm{M})$ and $K_{\mathrm{D}}$ values from Trp fluorescence $(7.5 \pm 3.2 \mu \mathrm{M})$ and ITC $(7.3 \mu \mathrm{M})$ as well as SPR $(3.75 \mu \mathrm{M})$ for DENV2 protease. We further observed competition of 1 with BPTI by ITC, SPR, and fluorescence quenching. NMR experiments confirmed that it interacted with the DENV2 protease active site (see Fig. S1 in Supplementary material). Compound 1 showed some differences in affinities for different dengue serotypes $\left(\mathrm{IC}_{50}\right.$ values varied between $6 \mu \mathrm{M}$ for DENV2 and $33 \mu \mathrm{M}$ for DENV4), and the Hill slopes obtained were close to 1, indicating a specific mode of inhibition [36,37]. The same is true for compounds $\mathbf{3}$ and $\mathbf{8}$.

On the other hand, compound $\mathbf{2}$ displayed one of the best $\mathrm{IC}_{50}$ values in our SAR analysis $(2.3 \pm 0.6 \mu \mathrm{M}$ for DENV2 protease). Despite its potency, no binding was detected by Trp fluorescence, and the addition of BPTI after the titration did not induce any decrease in fluorescence intensity. This was confirmed by ITC where no competition with BPTI was observed and again by the absence of binding in SPR. Hence, it is likely that compound $\mathbf{2}$ is a nonspecific inhibitor. This reasoning also applies to compound 7. Careful inspection of the enzyme inhibition data for WNV and DENV1-4 proteases revealed two variables as particularly useful criteria of specific binding. First, the inhibition curves obtained with $\mathbf{2}$ and $\mathbf{7}$ displayed steep transitions. This translated into steep Hill slopes, strongly suggesting that they act by a nonspecific mechanism [36,37]. Relying solely on Hill slopes, however, may be misleading. For example, compounds $\mathbf{3}, \mathbf{5}$, and $\mathbf{8}$ gave Hill slopes of approximately 2 (Table 1 ), yet data from fluorescence quenching experiments and ITC clearly showed that they were specific inhibitors. These examples reinforce our conclusion that it is important to use a repertoire of biochemical and biophysical techniques to accurately determine compound binding specificity during drug screening.

Second, $\mathrm{IC}_{50}$ values obtained with compounds $\mathbf{2}$ and $\mathbf{7}$ were very similar for WNV and DENV1-4, indicating that they inhibited all proteases equally well. This is unexpected considering that the S1 site of the WNV protease catalytic pocket differs from those of DENV1-4 proteases and NS2B residues forming S2 and S3 sites are also not well conserved between WNV and the different DENV serotypes. Moreover, the transition state analogue Bz-nKRR-H showed different inhibition properties with proteases from the different dengue serotypes (Table 1) and WNV [13]. We conclude that in the current SAR, similar $\mathrm{IC}_{50}$ values observed for the different serotypes, coupled with high Hill slopes, were indicative of nonspecific inhibition.

As described in this article, we also explored other biophysical techniques besides Trp fluorescence, such as NMR, ITC, and SPR, to evaluate the binding characteristics of compounds from our SAR study. Because our most active compounds showed $\mathrm{IC}_{50}$ values between 1 and $10 \mu \mathrm{M}$, they were tested at relatively high concentrations $(>100 \mu \mathrm{M})$ in both NMR and ITC. Thus, the major issue we encountered was low compound solubility that prevented meaningful analyses using these methods. Consequently, NMR and ITC offered a mostly qualitative observation (binding or no binding), whereas quantitative binding parameters (rather than binary answers) are paramount for understanding SAR. Because compounds identified during hit-to-lead and early lead optimization phases often have relatively low potency ( $>1 \mu \mathrm{M})$ and are usually hydrophobic in nature [38], compound insolubility in NMR and ITC would result in these compounds being eliminated from follow-up studies even if they are specific inhibitors. With SPR, we observed a correlation with $K_{\mathrm{D}}$ measured by fluorescence for most of the compounds except compound $\mathbf{5}$. The compound could have aggregated from nonspecific interactions with the immobilized protease or chip matrix. In contrast, we rarely faced solubility or aggregation problems in the fluorescence quenching assay with the concentra- tions of compounds tested (up to $40 \mu \mathrm{M}$ ) and were able to quantify the binding affinities of most specific compounds.

The Trp fluorescence assay presented here was a very useful tool for our drug discovery effort because it discriminated between specific and nonspecific compounds from our SAR study. This method has many advantages. First, small amounts of purified recombinant proteins can be readily used without the need to further label or tag them. Second, fluorescence spectroscopy tolerates a wide range of buffer conditions, salts, detergents, and reducing agents. Third, the binding assay can be done in 96- or 384-well formats, making this method amenable to automation further increasing the throughput. Fourth, the sensitivity of this method allows measurements of $K_{\mathrm{D}}$ values in the range from 0.1 to $20 \mu \mathrm{M}$. Below $0.1 \mu \mathrm{M}$ the shape of the binding curve would not permit a precise determination of the $K_{\mathrm{D}}$ value, whereas above $20 \mu \mathrm{M}$ the IFE would obscure fluorescence decrease induced by ligand-protein binding. Assays sensitive to this range of $K_{\mathrm{D}}$ values are of great value in the critical drug discovery phases of hit-tolead conversion and early lead optimization.

Because Trp is present in most proteins, the Trp fluorescence quenching assay presented here is applicable to other studies of protein-compound interaction. If Trp residues are absent or far from the binding site, they may be introduced by site-directed mutagenesis. The simplest manner to detect compound binding is via direct compound quenching of Trp fluorescence, as shown in this article, or by observing changes in the Trp emission maxima. Most compounds in drug discovery follow the Lipinski rules [38] and are largely hydrophobic, and often aromatic, molecules. Absorbance spectra of such compounds often span the spectral range from 270 to $400 \mathrm{~nm}$, making them suitable quenchers of tryptophan fluorescence. If a class of compounds lacked these spectroscopic properties, a known inhibitor that induces a fluorescence change on binding could be used as a competitor. The ease of implementing this technique makes it well-suited for drug discovery needs.

\section{Acknowledgments}

We thank Lim Siew Choo for assistance with the cloning of mutant Trp constructs and Dariusk Ekonomiuk and Shahul Nilar for performing some of the docking runs. NMR work carried out in the laboratory of Gottfried Otting was funded by the Australian Research Council.

\section{Appendix A. Supplementary data}

Supplementary data associated with this article can be found, in the online version, at doi:10.1016/j.ab.2009.08.013.

\section{References}

[1] G.S. Sittampalam, S.D. Kahl, W.P. Janzen, High-throughput screening: advances in assay technologies, Curr. Opin. Chem. Biol. 1 (1997) 384-391.

[2] S.A. Sundberg, High-throughput and ultra-high-throughput screening: Solution- and cell-based approaches, Curr. Opin. Biotechnol. 11 (2000) 47-53.

[3] B.K. Shoichet, Screening in a spirit haunted world, Drug Discov. Today 11 (2006) 607-615.

[4] S.L. Mcgovern, E. Caselli, N. Grigorieff, B.K. Shoichet, A common mechanism underlying promiscuous inhibitors from virtual and high-throughput screening, J. Med. Chem. 45 (2002) 1712-1722.

[5] B.Y. Feng, B.K. Shoichet, A detergent-based assay for the detection of promiscuous inhibitors, Nat. Protoc. 1 (2006) 550-553.

[6] A.J. Ryan, N.M. Gray, P.N. Lowe, C.W. Chung, Effect of detergent on "promiscuous" inhibitors, J. Med. Chem. 46 (2003) 3448-3451.

[7] G. Katzenmeier, Inhibition of the NS2B-NS3 protease: towards a causative therapy for dengue virus diseases, Dengue Bull. 28 (2004) 58-67.

[8] P.Y. Shi, Strategies for the identification of inhibitors of West Nile virus and other flaviviruses, Curr. Opin. Invest. Drugs 3 (2002) 1567-1573.

[9] T.J. Chambers, C.S. Hahn, R. Galler, C.M. Rice, Flavivirus genome organization, expression, and replication, Annu. Rev. Microbiol. 44 (1990) 649-688. 
[10] B. Falgout, R.H. Miller, C.J. Lai, Deletion analysis of dengue virus type 4 nonstructural protein NS2B: Identification of a domain required for NS2B-NS3 protease activity, J. Virol. 67 (1993) 2034-2042.

[11] F. Preugschat, C.W. Yao, J.H. Strauss, In vitro processing of dengue virus type 2 nonstructural proteins NS2A, NS2B, and NS3, J. Virol. 64 (1990) 4364-4374.

[12] S. Chanprapaph, P. Saparpakorn, C. Sangma, P. Niyomrattanakit, S. Hannongbua, C. Angsuthanasombat, G. Katzenmeier, Competitive inhibition of the dengue virus NS3 serine protease by synthetic peptides representing polyprotein cleavage sites, Biochem. Biophys. Res. Commun. 330 (2005) 12371246.

[13] J.E. Knox, N.L. Ma, Z. Yin, S.J. Patel, W.L. Wang, W.L. Chan, K.R. Ranga Rao, G. Wang, X. Ngew, V. Patel, D. Beer, S.P. Lim, S.G. Vasudevan, T.H. Keller, Peptide inhibitors of West Nile NS3 protease: SAR study of tetrapeptide aldehyde inhibitors, J. Med. Chem. 49 (2006) 6585-6590.

[14] K. Lohr, J.E. Knox, W.Y. Phong, N.L. Ma, Z. Yin, A. Sampath, S.J. Patel, W.L. Wang, W.L. Chan, K.R. Rao, G. Wang, S.G. Vasudevan, T.H. Keller, S.P. Lim, Yellow fever virus NS3 protease: peptide-inhibition studies, J. Gen. Virol. 88 (2007) 22232227.

[15] Z. Yin, S.J. Patel, W.L. Wang, W.L. Chan, K.R. Ranga Rao, G. Wang, X. Ngew, V. Patel, D. Beer, J.E. Knox, N.L. Ma, C. Ehrhardt, S.P. Lim, S.G. Vasudevan, T.H. Keller, Peptide inhibitors of dengue virus NS3 protease: II. SAR study of tetrapeptide aldehyde inhibitors, Bioorg. Med. Chem. Lett. 16 (2006) 4043.

[16] Z. Yin, S.J. Patel, W.L. Wang, G. Wang, W.L. Chan, K.R. Rao, J. Alam, D.A. Jeyaraj, X. Ngew, V. Patel, D. Beer, S.P. Lim, S.G. Vasudevan, T.H. Keller, Peptide inhibitors of dengue virus NS3 protease: I. Warhead, Bioorg. Med. Chem. Lett. 16 (2006) 36-39.

[17] S.A. Shiryaev, B.I. Ratnikov, A.V. Chekanov, S. Sikora, D.V. Rozanov, A. Godzik, J. Wang, J.W. Smith, Z. Huang, I. Lindberg, M.A. Samuel, M.S. Diamond, A.Y. Strongin, Cleavage targets and the d-arginine-based inhibitors of the West Nile virus NS3 processing proteinase, Biochem. J. 393 (2006) 503-511.

[18] V.K. Ganesh, N. Muller, K. Judge, C.H. Luan, R. Padmanabhan, K.H. Murthy, Identification and characterization of nonsubstrate based inhibitors of the essential dengue and West Nile virus proteases, Bioorg. Med. Chem. 13 (2005) 257-264.

[19] P.A. Johnston, J. Phillips, T.Y. Shun, S. Shinde, J.S. Lazo, D.M. Huryn, M.C. Myers, B.I. Ratnikov, J.W. Smith, Y. Su, R. Dahl, N.D. Cosford, S.A. Shiryaev, A.Y Strongin, HTS identifies novel and specific uncompetitive inhibitors of the two-component NS2B-NS3 proteinase of West Nile virus, Assay Drug Dev. Technol. 5 (2007) 737-750.

[20] N.H. Mueller, N. Pattabiraman, C. Ansarah-Sobrinho, P. Viswanathan, T.C. Pierson, R. Padmanabhan, Identification and biochemical characterization of small molecule inhibitors of West Nile virus serine protease by a high throughput screen, Antimicrob. Agents Chemother. 52 (2008) 3385-3393 (erratum: 53 (2009) 341).

[21] D. Ekonomiuk, X.C. Su, K. Ozawa, C. Bodenreider, S.P. Lim, Z. Yin, T.H. Keller, D. Beer, V. Patel, G. Otting, A. Caflisch, D. Huang, Discovery of a non-peptidic inhibitor of West Nile virus NS3 protease by high-throughput docking, PLoS Negl. Trop. Dis. 3 (2009) e356.

[22] J. Li, S.P. Lim, D. Beer, V. Patel, D. Wen, C. Tumanut, D.C. Tully, J.A. Williams, J. Jiricek, J.P. Priestle, J.L. Harris, S.G. Vasudevan, Functional profiling of recombinant NS3 proteases from all four serotypes of dengue virus using tetrapeptide and octapeptide substrate libraries, J. Biol. Chem. 280 (2005) 28766-28774.
[23] Y.L. Zhang, Z.Y. Zhang, Low-affinity binding determined by titration calorimetry using a high-affinity coupling ligand: a thermodynamic study of ligand binding to protein tyrosine phosphatase 1B, Anal. Biochem. 261 (1998) 139-148.

[24] A. Frostell-Karlsson, A. Remaeus, H. Roos, K. Andersson, P. Borg, M Hamalainen, R. Karlsson, Biosensor analysis of the interaction between immobilized human serum albumin and drug compounds for prediction of human serum albumin binding levels, J. Med. Chem. 43 (2000) 1986-1992.

[25] D.G. Myszka, Improving biosensor analysis, J. Mol. Recognit. 12 (1999) 279284.

[26] X.C. Su, K. Ozawa, H. Yagi, S.P. Lim, D. Wen, D. Ekonomiuk, D. Huang, T.H. Keller, S. Sonntag, A. Caflisch, S.G. Vasudevan, G. Otting, NMR study of complexes between low molecular mass inhibitors and the West Nile virus NS2B-NS3 protease, FEBS J. 276 (2009) 4244-4255.

[27] N. Majeux, M. Scarsi, A. Caflisch, Efficient electrostatic solvation model for protein-fragment docking, Proteins 42 (2001) 256-268.

[28] N. Majeux, M. Scarsi, J. Apostolakis, C. Ehrhardt, A. Caflisch, Exhaustive docking of molecular fragments with electrostatic solvation, Proteins 37 (1999) 88105.

[29] M. Cecchini, P. Kolb, N. Majeux, A. Caflisch, Automated docking of highly flexible ligands by genetic algorithms: a critical assessment, J. Comput. Chem. 25 (2004) 412-422.

[30] N. Budin, N. Majeux, A. Caflisch, Fragment-based flexible ligand docking by evolutionary optimization, Biol. Chem. 382 (2001) 1365-1372.

[31] P. Erbel, N. Schiering, A. D’arcy, M. Renatus, M. Kroemer, S.P. Lim, Z. Yin, T.H. Keller, S.G. Vasudevan, U. Hommel, Structural basis for the activation of flaviviral NS3 proteases from dengue and West Nile virus, Nat. Struct. Mol. Biol. 13 (2006) 372-373.

[32] S. Cook, E.C. Holmes, A multigene analysis of the phylogenetic relationships among the flaviviruses (family: Flaviviridae) and the evolution of vector transmission, Arch. Virol. 151 (2006) 309-325.

[33] A.E. Aleshin, S.A. Shiryaev, A.Y. Strongin, R.C. Liddington, Structural evidence for regulation and specificity of flaviviral proteases and evolution of the Flaviviridae fold, Protein Sci. 16 (2007) 795-806.

[34] B.W. Van Der Meer, G. Coker, S.-Y.H. Chen, Resonance Energy Transfer: Theory and Data, Wiley-CH, New York, 1991.

[35] B. Birdsall, R.W. King, M.R. Wheeler, C.A. Lewis Jr., S.R. Goode, R.B. Dunlap, G.C. Roberts, Correction for light absorption in fluorescence studies of proteinligand interactions, Anal. Biochem. 132 (1983) 353-361.

[36] R.A. Copeland, Enzyme Inhibitors in Drug Discovery: A Guide for Medicinal Chemists and Pharmacologists, Wiley-Interscience, New York, 2005.

[37] B.K. Shoichet, Interpreting steep dose-response curves in early inhibitor discovery, J. Med. Chem. 49 (2006) 7274-7277.

[38] C.A. Lipinski, F. Lombardo, B.W. Dominy, P.J. Feeney, Experimental and computational approaches to estimate solubility and permeability in drug discovery and development settings, Adv. Drug Deliv. Rev. 46 (2001) 3-26.

[39] B.R. Brooks, C.L. Brooks, A.D. Mackerell, L. Nilsson, R.J. Petrella, B. Roux, Y. Won, G. Archontis, C. Bartels, S. Boresch, A. Caflisch, L. Caves, Q. Cui, A.R. Dinner, M. Feig, S. Fischer, J. Gao, M. Hodoscek, W. Im, K. Kuczera, T. Lazaridis, J. Ma, V. Ovchinnikov, E. Paci, R.W. Pastor, C.B. Post, J.Z. Pu, M. Schaefer, B. Tidor, R.M. Venable, H.L. Woodcock, X. Wu, W. Yang, D.M. York, M. Karplus, CHARMM: the biomolecular simulation program, J. Comput. Chem. 30 (2009) 1545-1614.

[40] W.L. Delano, The PyMOL Molecular Graphics System, DeLano Scientific, San Carlos, CA, BI050307G, 2004. Available from: <http://www.pymol.org>. 